\title{
The Effects of Labor Supply Shocks on Labor Market Outcomes: The Israeli-Palestinian Conflict
}

\author{
Hani Mansour \\ University of California, Santa Barbara
}

Updated: April 10th, 2007

I thank Peter Kuhn, Javier Birchenall, Olivier Deschenes, Kelly Bedard, and Philip Babcock for numerous comments and continuous support, and the Institute on Global Conflict and Cooperation for generous financial support. 


\begin{abstract}
Since September 2000, the mobility of Palestinian workers into Israel has been permanently restricted. The new border policies generated an increase of about forty percent in the supply of workers competing for local jobs in the West Bank. Moreover, Israel restricted the movement of Palestinians within the West Bank. The exogeneity of this labor supply shock, a result of restrictive border policies, and the division of the West Bank into local labor markets provide a unique environment to study the effects of labor supply shocks on labor market outcomes. Using the Palestinian Labor Force Survey for the years 2000-2004, two empirical strategies are used to identify the effects of the supply shock on wages and employment patterns. The results suggest that a 10 percent increase in the labor supply of unskilled workers reduces their wages by about 25 percent. No effects on wages are found among the skilled workers. The employment of unskilled workers seems to adjust much slower than for skilled individuals, generating a substantial rate of unemployment among the unskilled. The results will be used to analyze counterfactual policies that are at the core of any future agreement between Israel and the Palestinians, such as border controls and the return of Palestinian refugees to the West Bank.
\end{abstract}

JEL Codes: J61, J21,D74,C21

Keywords: Immigration, Labor Supply Shocks, Labor Demand Shocks, Israel, Palestine, Border Controls. 


\section{Introduction}

At the beginning of this decade, and as a consequence of the second Palestinian uprising, the number of Palestinian workers who commute to Israel decreased by more than fifty percent. The persistence of the restriction on mobility into Israel generated an increase in the supply of workers competing for local jobs in the Palestinian market. Moreover, Israel restricted the mobility of Palestinians within the West Bank dividing the region into separate local markets. A competitive labor market model predicts that an increase in the supply of labor reduces the wages of competing factors. Despite this clear prediction, numerous empirical papers that study the impact of such an increase on wages and employment provide different and at times contradictory results (Borjas, 2003). This paper takes advantage of the unique environment that the Palestinian market offers to study the effects of a supply shock on the labor market. Since the period under consideration is characterized by high political instability that may have affected wages and employment, the empirical analysis offers alternative approaches to identify the supply shock separately from the effects of political instability.

Aside from contributing to the literature regarding the effects of labor supply shocks, understanding the response of the Palestinian labor market to the increase in the supply of workers and quantifying the effects of the political instability on wages allows us to estimate the effects of counterfactual policies that are at the core of the Israeli-Palestinian conflict. For example, what are the economic implications of completely closing the border with Israel? What are the conditions needed to create a Palestinian economy independent from the Israeli one? What are the potential effects of the return of Palestinian refugees to the West Bank or 
Gaza - a wave that will create further pressure on the supply of labor?

During 1970-1993, about 40-50 percent of Palestinian workers commuted on a daily basis to work in Israel. Since September 2000, when the second Palestinian uprising started, the percentage of Palestinians commuting to Israel dropped dramatically. By 2004, only 15 percent of West Bank residents and eight percent of Gaza residents worked in Israel. Two key features of this change make the Palestinian labor market a good place to examine the impact of labor supply shocks on labor market outcomes.

First, mobility between different cities within the West Bank has been extremely restricted since the beginning of 2000. As a result, if comparable cities experience different labor supply shocks, then cross-city differences in the increase in labor supply can be used to identify the effects on wages and employment. The use of variation in immigrant inflow to different, but comparable, cities to identify the effects of immigration on wages has been widely used in previous studies (Card, 1990). These studies tend to find very small (if any) effects on wages of natives (Borjas, 1994). The concern regarding this approach (Borjas,2003) is that changes in the mobility of workers across cities, induced by immigration flows, happens fast enough and masks any effects that we would expect to see on wages. The lack of mobility between Palestinian cities and the variation in the supply shock across them provide an ideal environment to study the effects on wages using this approach.

Second, the supply shock was a result of an exogenous event - restrictive border controls as a result of a civil uprising. The increase in labor supply affected various groups of workers of different skills and ages. Variations in the changes in 
the supply of workers over time and across skill groups within each of the West Bank cities allows the investigation of the short-run effects of such changes and reveals the relationship among workers of different types. While the assumption about the separability of labor markets across cities (in the United States) is often criticized in the literature (Borjas, 1996), the restrictions on mobility due to the Israeli-Palestinian conflict offers a unique opportunity to implement this strategy. However, the main challenge when using any approach in the Palestinian context is to disentangle the effects of the increase in the labor supply separately from the direct effects of the political instability. A detailed explanation on how this issue is treated will be discussed in later sections of the paper.

The second section of the paper outlines the most notable events in the PalestinianIsraeli conflict and their economic relations. It is followed by a literature review in the third section. The fourth section discusses the data. The identification strategies and results are presented in the fifth and sixth sections. The seventh section concludes.

\section{Background}

After the Israeli occupation of the West Bank of the Jordan River and the Gaza Strip in 1967, a large proportion of Palestinian workers commuted to Israel on a daily basis, mainly to supply labor services in the construction, manufacturing, and agriculture industries. By 1982, 48 percent of the men aged 18-64 in Gaza and 36 percent in the West Bank were employed in Israel (Angrist, 1996). During the late 1980s and early 1990s, the flow of Palestinian labor to Israel experienced many fluctuations as a response to major political events, such as the first Palestinian uprising (1987-1993), the Gulf War (1991), the Oslo agreement (1993), and also 
as a consequence of new Israeli policies that aimed to reduce the dependency on Palestinian unskilled labor. The most noted policy was to allow foreign nonPalestinian workers to enter the Israeli labor market. According to the Israeli Central Bureau of Statistics (2004), during 1995-2004 about 60 percent of foreign non-Palestinian workers were allocated in the same industries that traditionally hosted Palestinian workers. Figure 1 depicts the number of Palestinians employed in Israel for the 1990-2005 period. The focus of this paper is to analyze the long and short run effects of the increase in the Palestinian domestic labor supply after September $2000 .^{1}$

The Oslo agreement, signed between Israel and the Palestinian Liberation Organization (PLO) in 1993, initiated one of the biggest changes in the Palestinian economy. In 1994-1995, Israel withdrew from parts of the Gaza Strip and the West Bank, and a new Palestinian Authority was established. Responsibilities in education, health, taxation, and tourism were transferred to the new Authority, while border controls with Israel, Jordan, Egypt, and between Gaza and the West Bank remained under exclusive Israeli control.

The 1993 Declaration of Principles (DOP) did not stop the mutual violence between the parties. The Hebron massacre, the bus bombings carried out by HAMAS in early 1996, the expansion of settlements in the West Bank, and the corruption of the Palestinian Authority were major obstacles to reach political stability. ${ }^{23}$

\footnotetext{
${ }^{1}$ The 1993-1997 is also characterized by a reduction in the number of Palestinians commuting to Israel that might have had an effect on domestic wages and employment. It is not analyzed in this paper because reliable data is not available.

${ }^{2}$ In February 25, 1994, Baruch Goldstein entered the Ibrahimi mosque in Hebron and murdered twenty-nine Palestinians.

${ }^{3}$ During the first three years since the DOP were signed, the settler population grew by 39 percent to 145,000; only 16 percent of this growth was due to natural increase (Joel
} 
Periods of high instability, as Figure 1 shows, are correlated with reductions in the number of Palestinians commuting to Israel. In September 2000, the mutual violence between Israel and the Palestinians culminated, when as a response to the visit of Ariel Sharon to the Haram al-Sharif/Temple mountain, the second Palestinian uprising (the al-Aqsa Intifada) started. Palestinian movement to Israel was severely limited, and the number of workers commuting to Israel dropped sharply, which caused a large labor supply shock in the Palestinian domestic markets.

According to B'Tselem - The Israeli Information Center For Human Rights in the Occupied Territories, during September 2000-October 2006, 3898 Palestinians were killed by Israeli security forces or by Israeli civilians, and 1011 Israeli civilians were killed by Palestinians. However, the political instability since September 2000 has differed in intensity and character among cities within the West Bank, between the West Bank and Gaza, and over time. For example, in March 2002 the Israeli forces invaded some Palestinian cities for the first time since 1994. As a consequence, 2002 was characterized by a high number of fatalities and days under curfew. For a more detailed description of the different periods of violence during 2000-2004, see Jaeger and Paserman (2005).

Along with the changes in the border policies toward foreign non-Palestinian workers (which aimed to lower the demand for Palestinian labor), Israel responded to Palestinian attacks and local disruptions by enacting a number of policies that affected Palestinian mobility within the West Bank and the Gaza Strip and into Israel. These policies include:

Beinin, 2005, based on Peace Now, Settlement Watch-Report No. 8, http://www.peacenow.org/watch/watch2.htm). 
1. In 1990, Israel reduced the number of work permits issued to Palestinians and changed group permits (based on age and marital status) to individual ones.

2. Curfews were imposed on Palestinian cities, mainly after the re-invasion of 2002.

3. Different levels of external and internal closures: while internal closures restrict mobility within the West Bank (mainly though permanent and temporary checkpoints), the external ones imply a complete closure of the borders with Israel.

4. In the summer of 2002, Israel began to build a "separation" wall, a physical concrete wall 26 feet high around cities and urban neighborhoods in the West Bank. The first phase of construction was completed in 2003 and covered the Northern parts of the West Bank, around Jenin, Qalqilya and Tul-Karem. By 2004, parts of the wall were also completed around Jerusalem, isolating Ramallah and Bethlehem from Jerusalem. The wall in the Southern part of the West bank is yet to be completed.

\section{Related Literature}

The effects of labor supply shocks are widely studied in the immigration literature. A model of a competitive labor market in which the demand for labor is not perfectly elastic predicts that an increase in the supply of workers should lower the real wage. Although the theoretical implication of such an increase is straightforward, numerous empirical studies in the literature fail to provide consistent evidence that the wages of natives react to such an influx. Borjas (2003) claims that "the existing evidence provides a mixed and confusing set of results. 
The measured impact of immigration on the wage of native workers fluctuates widely from study to study, but seems to cluster around zero."

The traditional strategy to identify the effects of labor supply shocks on labor market outcomes is to use the geographical clustering of immigrants across cities. Differences in wages or employment patterns across cities that experienced different influx of workers would identify the impact of immigration. In his paper on the impact of the Cuban immigration of 1980 on the Miami labor market, Card (1990) compares the wages and employment patterns of Miami with four cities: Atlanta, Houston, Los Angeles, and Tampa-St. Petersburg for the years 1979-1985. He concludes that the seven percent increase in Miami's labor force as a result of the Cuban immigration had no effect on the wages or unemployment rates of unskilled workers. This study is criticized because it treats the local labor markets as separate and ignores the fact that workers can move easily across cities, which results in equalizing economic conditions across regions.

A different approach, developed by Borjas (2003), exploits the variation in the influx of immigrants across education-experience groups using data from the 1960-1990 U.S. Decennial Censuses. Workers with the same level of education and experience are assumed to be perfect substitutes. The impact of immigration on wages is then identified from changes in education-experience cells over time. His analysis indicates that a ten percent increase in supply reduces wages by three to four percent. One potential problem in this study is that capital is assumed to be fixed over a long period of time and as a result the impact of immigration on wages is overestimated.

Ottaviano and Peri (2005) classify the workers in education-experience cells 
similar to the Borjas (2003) grouping. However, they make two different key assumptions. The first one treats U.S. and foreign workers with the same level of education and experience as imperfect substitutes, and the second allows for endogenous capital accumulation. Despite the negative impact of the relative skill levels of immigrants on the relative wages of U.S. workers, their results suggest that overall immigration generates a large positive effect on the average wages of native workers.

The Palestinian experience provides a suitable environment to address most of the problems associated with the approaches mentioned above. The security measures imposed by Israel since 2000 divided the once-homogenous West Bank region into separate local labor markets. Since mobility between cities was severely limited, any labor supply shock would have been absorbed by each of the local markets. ${ }^{4}$ Differences between different skill-experience groups can be also taken advantage of to identify the effects of the supply shock. Moreover, the assumption of holding capital fixed in the Palestinian context is reasonable because of the short period of time under consideration. However, it is important to keep in mind that the increase in the Palestinian domestic labor supply was accompanied, and may have been caused, by a civil uprising that likely has a direct effect on wages. Any identification strategy will have to find a way to separate those two effects.

Several studies have considered the Palestinian-Israeli labor markets both before and after the Oslo agreements. Angrist (1996) uses quarterly time-series on person-days under curfew in the West Bank and Gaza as an exogenous supply

\footnotetext{
${ }^{4}$ According to weekly reports of the U.N. Office for the Coordination of Human Affairs in the occupied Territories restrictions on mobility between Palestinian cities in the West Bank were often imposed on incoming and outgoing goods, affecting the trade and transfer of products between the different regions.
} 
shock to identify the effects on wages paid to Palestinians employed in Israel. His analysis utilizes data from the 1981-1991. He finds that the observed covariance between Palestinian wages and days worked generates a short-run elasticity in the demand for Palestinian labor between -1 and -2 .

In more recent studies, Aranki (2004) uses data from the Palestinian Labor Force Survey for the period 1999-2003 to estimate the effect of the Israeli closure policy on Palestinian wages and employment. His results suggest that the Israeli policy of closure has a significant effect on wages and workdays of Gazans employed in Israel only. No such effects are found in the West Bank or for workers working locally in Gaza. He estimates a traditional wage equation, then uses the predicted quarter fixed effect component to regress it against the closure variable. The problem with this approach is mainly an omitted variable problem. Closures are correlated with other political instability measures, such as internal checkpoints, the construction of the wall, military invasions, etc. Not controlling for these measures will result in a biased estimate. Since those measures are correlated with closures in different ways, it is hard to point out the direction of the bias in his estimates.

Finally, Friedberg and Sauer (2004) utilize data from the 1991-1995 period to study the effects of the presence of foreign non-Palestinian workers on the wages, earnings, and employment of Palestinians employed in Israel. Their findings suggest that foreign non-Palestinian workers reduce the employment level of Palestinians in Israel. Both OLS and IV estimates show that the mean daily earnings among Palestinians from Gaza employed in Israel are reduced, but no such effect is found for Palestinians from the West Bank who work in Israel. 
This study primarily focuses on the effects of the increase in the Palestinian labor supply, induced by restrictions on mobility to Israel, on wages and employment in the West Bank. Rather than estimating the reduced form effects of the Israeli policies (e.g. foreign workers, closures) on labor market outcomes, the empirical strategies that I employ attempt to identify the response of the labor market to an increase in the supply of workers separately from the direct effects of the political instability. This distinction is useful because it provides tools to analyze future border policies between Israel and the Palestinians even when the political stability is restored.

\section{Data}

\subsection{Overview}

Most of the recent literature regarding the Palestinian labor market treats the West Bank and the Gaza Strip regions separately (Friedberg and Sauer, 2004; Aranki, 2004). ${ }^{5}$ This separation is necessary because the two regions are geographically distant with no mobility of workers between them and have different economic characteristics. In this paper I focus on the labor market in the West Bank (including East Jerusalem) and exclude Gaza from the analysis. This exclusion is due to the identification strategies I use. For example, while different cities in the West Bank are roughly comparable in their characteristics this assumption is not valid for the Gaza Strip.

The data on the Palestinian workers is from the Palestinian Labor Force Survey

\footnotetext{
${ }^{5}$ The West Bank constitutes about two thirds of the Palestinian population. For a more detailed comparison between the labor market in Gaza and in the West Bank see Kleiman (1992).
} 
(PLFS) for the years 1997-2004. Daily wages are reported only for 2000-2004; hence, it will be the main sample used for the analysis. The 2000-2004 sample includes all men aged 18-65 in the West Bank region and excludes self employed and unpaid family individuals. The sample has 81,464 observations at the individual level, and provides a wide range of demographic and labor status information. Individuals also report their main workplace location (e.g. Israel, the West Bank, or none), and 46 percent of the sample report daily wages. Real daily wages are in 1996 prices and are deflated using the consumer price index on a quarterly basis. Women are excluded from the analysis since their labor force participation rates are small (around the 10-11 percent) and does not change over the sample period.

In 1995, the Palestinian Central Bureau of Statistics (PCBS) was established, and the first labor force survey was conducted in the third quarter of 1995. Previous studies on the Palestinian labor market used the Territories Labor Force Survey (TLFS). This survey was conducted by local enumerators employed by the Israeli Civil Administration in the Occupied Territories.

The PLFS data set is especially attractive because it was collected by Palestinian enumerators. Hence, measurement errors due to misreporting, especially for variables related to working in Israel, are expected to decrease. Despite periods of severe restrictions on mobility, the survey was conducted with very few interruptions, mainly because local enumerators were employed in different cities so that restrictions on mobility between cities in the West Bank did not affect the collection of the data.

Data on fatalities in the West Bank and Israel, as a result of the conflict, were gathered by B'Tselem and are considered reliable both by the Israelis and Pales- 
tinians. The data is on a monthly basis by region within the West Bank. The dates and duration of curfews starting in June 2002 (when Israel re-occupied most of the Palestinian cities) were gathered by the Palestinian Red Crescent. Information on the path of the separation wall (discussed in section two) and its rate of completion were obtained from the U.N. Office for the Coordination of Human Affairs in the Occupied Territories (OCHAOPT: http://www.ochaopt.org/).

\subsection{Descriptive Statistics}

Table 1 reports some of the main characteristics of the labor market in the West Bank over the period 1997-2004 for men, aged 18-65. Labor force participation decreased over the $2000-2004$ period from 79 percent to 70 percent. The fraction of workers employed from the whole population of men decreased dramatically, from 66 percent in 2000 to 46 percent in $2004 .^{6}$ The average level of schooling was stable at around 10 years.

Historically, the supply of Palestinian workers to Israel was never stable, and it would decrease as a result of political events; however, these reductions were temporary, and the fraction of Palestinian men working in Israel would rise again (Angrist, 1996). Even during the 1990s, when Israel opened its labor market to foreign non-Palestinian workers, about 35-40 percent of Palestinians still commuted to Israel. The change in the fraction of workers after the year 2000 was significantly different from past experiences. It dropped from 33 percent in 2000 to 15 percent in 2004, a roughly fifty percent change, and is not expected to rise anytime in the near future; hence, the supply shock can be viewed as persistent and is expected

\footnotetext{
${ }^{6}$ Men who reported Israel as their workplace location but were absent from work due to closures were considered as unemployed.
} 
to have long-lasting effects on the local market.

\subsection{Composition Effects}

A common problem in the immigration literature is that the observed reduction in wages might be a result of a "composition" effect, Friedberg (1995). The idea is that the observed city-level wages are composed of the wages of natives and of the new immigrants. Therefore, if immigrants earn less than natives (for example because of skill differences), then the average wages in cities with higher proportions of immigrants will be lower, even if immigrants have no adverse impact on the wages of natives. Since in most data sets it is impossible to distinguish immigrant earnings from native earnings, it is not possible to identify these two effects separately.

Since individuals who were employed in Israel in the past (and are not anymore) cannot be identified, decomposing the wages among past commuters and non-commuters is not possible. However, we can use changes in observable determinants of wages (such as education, age and industry) to address the likely impact of composition changes on local average wages. Table 2 reports mean age, education, and marital status for three different samples for the years 1997-2004: workers employed in the West Bank, workers employed in Israel, and unemployed individuals. The distribution of skills over time seems to be remarkably stable across the three populations. The average characteristics of workers still employed in Israel hardly moves despite their numbers being cut by more than half, and the average characteristics of the unemployed did not change much despite their numbers more than doubling. This suggests that those who could not commute to Israel became unemployed, and thus no compositional change in observed skills 
occurred for the employed in the West Bank. The figures in Table 2 for the workers employed locally reinforce this argument. In fact, there is a slight increase in the mean years of education, age, and marital status, suggesting that the locally employed population got slightly more skilled, so the true decline in the price of labor may be even greater than the raw numbers suggest.

To further explore the potential impact of composition changes, I estimate the following wage equation that describes changes in average Palestinian wages conditional on demographic characteristics, separately for the years 2000-2004, and where the samples are restricted to include only workers employed locally:

$$
\ln W_{i t}=\sum_{q} t_{i q} \alpha_{q t}+\sum_{s} a_{i s} \gamma_{s t}+\sum_{c} b_{i c} \delta_{c t}+\sum_{d} g_{i d} \eta_{d t}+m_{i} \beta+r_{i} \sigma+\epsilon_{i t}
$$

where $t_{i q}$ is a dummy variable indicating whether observation $i$ is observed in quarter $q, a_{i s}$ is a dummy that indicates if $i$ is in education group $s, b_{i c}$ is a dummy that indicates if $i$ is in age group $c, g_{i d}$ is a dummy for industry $d, m_{i}$ is a marital status dummy, and $r_{i}$ indicates whether $i$ lives in a refugee camp. ${ }^{7}$ After obtaining the estimates I decompose the decline in average wages between the year 2000 (before the supply shock) and each of the years that follow using the Oaxaca method, Oaxaca (1973). This decomposition helps in determining which percentage of the decline in average wages is due to changes in the average characteristics and which is due to changes in the coefficients.

\footnotetext{
${ }^{7}$ The education groups indexed by $s$ are 13-15 years, 16 or more years. The age groups indexed by $c$ are $25-34,35-44,45-54,55-64$. The industries indexed by $d$ are agriculture, manufacturing, construction, commerce, hotels and restaurants, and services. The omitted industry group is transport and communication.
} 
The results are in line with the raw data in Table 2. In 2000-2001, 17 percent of the decline in wages is due to changes in the mean characteristics, but this figure drops to 5 percent when the average decline of 2000-2002 is decomposed and becomes negligible for the years 2000-2003 and 2000-2004. This analysis provides more evidence that changes in the average wages are not due to composition effects but are a result of other factors. ${ }^{8}$

\section{Preliminary Analysis: A Difference-in-Difference Approach}

As mentioned in previous sections, the source of the increase in the Palestinian labor supply is the decrease in the number of workers who are able to commute to Israel. Formally, individuals in the sample are categorized into one of four exhaustive and mutually exclusive categories: employed locally, employed in Israel, unemployed, and non-participants. ${ }^{9}$ The domestic labor supply is defined as:

$$
\begin{gathered}
\text { Domestic Labor Supply }=\text { workers employed locally } \\
+ \text { unemployed }
\end{gathered}
$$

An alternative measure of the domestic labor supply that endogenizes the participation decision adds non-participants to equation (2). Most of the cities in the West Bank experience both labor supply and demand shocks in the wake of

\footnotetext{
${ }^{8}$ The results of estimating equation (1) and the Oaxaca decomposition will be provided upon request of the reader.

${ }^{9}$ Employed individuals who did not report a workplace locations were dropped out of the sample. Over the 2000-2004 sample period 20 such observations were dropped.
} 
political instability. How can we identify the supply shock effect separately from the direct effect of the civil unrest on labor market outcomes? One approach is to construct a "control" group that did not experience a significant supply shock but experienced the same demand shock as the "treated" group; we can then difference out the demand shock and identify the parameter of interest.

Although the different regions in the West Bank have similar characteristics, there are important differences between East Jerusalem and the rest of the West Bank cities. ${ }^{10}$ East Jerusalem residents do not need a work permit to commute to Israel, and they are unaffected by either closures or curfews imposed by the Israeli government. However, unemployment did rise in East Jerusalem over the sample period mainly because local employment decreased indicating that the city did experience a demand shock.

The first four columns in Table 3 report the percentage of men in each of the above categories from the total population in East Jerusalem and the rest of the West Bank cities separately. ${ }^{11}$ Column five reports the share of domestic labor supply, as defined in equation (2), from the population of labor force participants. Column six reports a different measure of the domestic labor supply in which nonparticipants are included (in both the numerator and denominator). The figures for the year 2000 include the first three quarters before the start of the second Intifada (the pre-treatment period). The fourth quarter of the year 2000 is included in the 2001 figures.

\footnotetext{
${ }^{10}$ East Jerusalem was annexed by Israel in 1967. However, Palestinians living in East Jerusalem do not carry an Israeli nationality. Despite the annexation, East Jerusalem is considered an important commercial and cultural center that serves Palestinians living in the rest of the West Bank.

${ }^{11}$ East Jerusalem includes all the urban areas that can access Israel at all times. Rural areas are included with the West Bank cities.
} 
In both regions, East Jerusalem and the rest of the West Bank, there is an increase in the percentage of unemployed men (column 3). The source of this increase, however, differs. While most of the increase in unemployment in East Jerusalem is coming from a reduction in the percentage of workers employed locally, the increase in the rest of the West Bank in the share of unemployed workers comes mainly from a reduction in the percentage of workers commuting to Israel.

Although the share of workers who commute to Israel from East Jerusalem decreased as well, especially in the year 2002, its magnitude is much smaller than in the rest of the West Bank. This is also reflected in the calculation of the domestic labor supply. The share of domestic labor supply in East Jerusalem from all labor market participants increased from 55 percent in 2000 to 61 percent in 2004, a 10 percent increase, the corresponding figures in the rest of the West Bank are 63 percent in 2000 to 88 percent in 2004, a 40 percent increase.

The proposed estimator $\theta_{t}$ that identifies the supply shock is:

$$
\theta_{t}=\left(\overline{W_{w b, t}}-\overline{W_{w b, 00}}\right)-\left(\overline{W_{J, t}}-\overline{W_{J, 00}}\right), t=2001, \ldots, 2004
$$

where $\overline{W_{i, t}}$ is the mean of the natural logarithm of the real daily wages in the West Bank and East Jerusalem respectively in year $t$. The sample excludes wages earned in Israel. Before I address the assumption underlying this estimator it is useful to show that there is no mobility across West Bank cities induced by the change in the ability to commute to Israel. This is important since mobility of workers across cities might mask the effects on wages. The lack of mobility implies 
that the increase in the supply in each market is absorbed locally and is expected to affect wages and employment. Table 4 provides evidence in favor of this fact. It reports the percentage of workers (from the total population of employed men) who work in the same city, workers who commute to another city in the West Bank, and workers who commute to Israel. Column 2 in Table 4 shows that the percentage of workers who do travel to a different city in the West Bank did not change over the sample period. ${ }^{12}$ However, Table 4 does not provide any information about permanent migration across cities in the West Bank or from cities in the West Bank to other countries. Considering the traditional structure of the Palestinian society and the period of instability under consideration it does not seem plausible that significant internal permanent migration is occurring, especially that all cities experienced a demand shock. Regarding the ability to emigrate outside of the West Bank, although it is a possibility, it seems to be a feasible option only among skilled workers because of the high costs of such a decision.

Assuming that composition effects are negligible, the main assumption needed to identify $\theta_{t}$ is that both regions, East Jerusalem and the rest of the West Bank, experienced similar political instability. In other words, both regions experienced a similar demand shock, while only the rest of the West Bank experienced an additional supply shock. If East Jerusalem did in fact have a small supply shock, or in contrast, a bigger demand shock compared to the rest of the West Bank, then $\theta_{t}$ is a lower bound of the true parameter. ${ }^{13}$

\footnotetext{
${ }^{12}$ The figures reported in Table 4 include all the cities in the West Bank. I repeated the same analysis using the data from each city individually. The percentage of workers who commute to a different city in the West Bank remains stable in all of them.

${ }^{13} \mathrm{I}$ am trying to motivate this assumption by collecting data on the demand trends in major industries such as tourism, manufacturing, and services. At this point, I have collected data on the number of tourists in both regions and the trends look very similar. This is not enough
} 
The regression that captures the difference-in-difference estimator described in equation (3) is:

$$
\ln W_{i t}=\beta_{0}+\left(W_{i t} \times T_{i t}\right) \theta_{t}+T_{i t} \gamma_{t}+\delta_{i} W B_{i t}+\epsilon_{i t}
$$

where $\ln W_{i t}$ is the natural logarithm of the wage earned locally by individual $i$ in year $t . T_{i t}$ is a set of post-treatment year dummies, $W B_{i t}$ is a dummy that equals one if the worker is not from East Jerusalem in year $t$, and $\epsilon_{i t}$ is an error term. In this setting, with no additional controls, the vector of coefficients $\theta_{t}$ is the difference-in-difference estimator described in equation (3), Angrist (1999).

The first column of Table 5 presents the basic estimates of $\theta_{t}$ with no additional controls. The second column adds to the regression a standard set of socioeconomic controls. These controls include age-group dummies, education-group dummies, a dummy for marital status, and three quarter dummies. Although individuals might have changed the industry they work in as a result of the supply or demand shocks, the specification in the third column adds to the controls of column 2 industry dummies. Since Unskilled workers constitute the majority of workers who commute to Israel, columns 3, 4, and 5 repeat the analysis but restrict the sample to include only unskilled workers. ${ }^{14}$

All the estimates, except for those of 2001, are statistically significant. There though, since tourism constitutes a bigger share of the East Jerusalem economy.

${ }^{14}$ Unskilled workers are defined as men with 12 years of education or less. Alternatively, I define them as those with schooling years that are less than the mean plus one half of the standard deviation of years of schooling for a year-of-birth cohort. For example, workers who were born before 1944 are considered unskilled if they have 9 years of education or less. However, unskilled workers that were born after 1955 are defined as unskilled if they have 12 years of education or less. Both definitions yield similar results and I choose to work with the first for simplicity. 
are two possible explanations why the effects on wages do not appear in 2001. The first is that wages are rigid and as a result do not move immediately with the increase in supply. The second is that workers who are unable to commute to Israel do not look for jobs in the local market immediately, and initially do not perceive the shock as persistent. This is consistent with the fact that the effect on wages appears starting from 2002 while the effect on the probability of employment (reported in Table 6) appears immediately after the shock.

To understand the magnitude of the estimates in Table 5 it is useful to relate them to the increase in the domestic labor supply. For example, the domestic labor supply (when participation is exogenous) increased from 63 percent in 2000 to 89 percent in 2002 - a 41 percent change (see Table 3, column 5). The estimate of -0.214 for the year 2002 (column 1, row 2), then, implies that a 10 percent increase in the share of domestic labor supply decreases domestic wages by about 4.70 percent. The corresponding figures for 2003 and 2004 are 5.22 and 4.74 percent reduction in wages, respectively (corresponds to a 38 percent change in the supply in 2003 and 40 percent in 2004, see Table 3). ${ }^{15}$

The estimates in Table 5 (column 4-6) are slightly bigger when the sample is restricted to include only unskilled workers. However, the increase in the domestic supply among unskilled workers is bigger as well. The estimates imply that a 10 percent increase in the domestic labor supply reduces the wages of unskilled workers by 4.12, 4.6, and 3.9 percent, respectively, for the years 2002-2004 (column 4 , rows 2-4, the increase in the supply for unskilled workers is 55 percent, 50

\footnotetext{
${ }^{15}$ When participation is endogenous, the corresponding reduction in wages to an increase of 10 percent in the supply of labor are a reduction of 5.84 percent in 2002, 6.61 percent in 2003, and 6.31 percent in 2004 .
} 
percent, and 52 percent for the years 2002-2004). Adding age, education, marital status, quarter controls, and industry dummies slightly reduces the magnitude of the effect. ${ }^{16}$

Table 6 repeats the same estimation but changes the dependent variable to be a dummy that equals 1 if the worker is not employed (unemployed or out of the labor force) and zero if the worker is employed.

The estimates are all statistically significant, and the increase in the probability of non-employment appears immediately after the start of the second uprising. Taking the changes in the supply of workers into account, the estimates imply that in 2001 (column 1, row 1), for example, a 10 percent increase in the domestic labor supply increases the probability of non-employment by about 5 percentage points. The corresponding figures for the years 2002-2004 are in the range of about 3.5 percentage points increase in the probability of non-employment.

For the unskilled workers a 10 percent increase in the domestic labor supply increases the probability of non-employment by about 5 percentage points in 2001 and by about 3 percentage points in 2002-2004. Adding controls reduces these magnitudes slightly but does not change them substantially.

The concern with the difference-in-difference approach, in the context of the Palestinian labor market, is that the levels of political instability that affected East Jerusalem and the other cities of the West Bank are different. To further motivate the validity of this assumption, I redefined the treatment group to include cities that geographically surround East Jerusalem. These cities are Bethlehem,

\footnotetext{
${ }^{16}$ The estimates when the sample is restricted to include only skilled workers are statistically insignificant. This might be due to small sample size.
} 
Ramallah, and Jericho. They surround Jerusalem, and hence it is more reasonable to assume that the political instability affected them and Jerusalem equally. The estimates of this experiment are very similar (point estimates and standard errors) to the results reported in Tables 5 and 6 . Alternatively, redefining the treated group to include all the cities that are further away from East Jerusalem produces point estimates that are slightly smaller, with bigger standard errors, compared to the estimates reported in Tables 5 and 6 . However, they are in the same range and statistically significant. This implies that including all the cities in the West Bank in the treated group and imposing the assumption that all of them experience a similar demand shock as the one East Jerusalem experience is not perfect but a reasonable assumption to make.

\section{A Parametric Approach}

An alternative, but related, strategy for identification is to use the variation in the percentage change in the local labor supply within a city in the West Bank and to control for the demand shock explicitly by including measures of political instability that vary across cities and over time. This approach although takes advantage of the separability of the labor markets across Palestinian cities, it relaxes the assumption that the demand shock is similar across them. To start, it is useful to present a theoretical model that describes the adjustment of labor markets to an increase in the supply of labor.

Following Lalonde and Topel (1991), assume that a concave production function in each of the separate Palestinian labor markets is represented by: 


$$
Q_{c t}=\alpha_{c} F\left[L_{s c t}, L_{u c t}\right]
$$

In equation (5), $Q_{c t}$ represents total output in city $c$ at time $t$ and is a function of two types of labor aggregates: skilled labor - $L_{\text {sct }}$ and unskilled labor $-L_{u c t}$. The parameter $\alpha_{c}$ is a city-specific shifter of the production function and does not affect relative wages of the different skill groups. ${ }^{17}$

Given the production function, the marginal product (wage) for the skilled and unskilled labor is

$$
W_{j c t}=\alpha_{c} F_{j}\left[L_{s c t}, L_{u c t}\right], j=s, u
$$

where $F_{j}=\partial F(\cdot) / \partial L_{j}$. In $\log$ terms, the wage of skill group $j$ in city $c$ at time $t$ is

$$
\log W_{j c t}=\log \alpha_{c}+\log F_{j}\left[L_{s c t}, L_{u c t}\right], j=s, u
$$

In order to transform (7) into an empirical specification, I will first expand the second term on the right-hand side to first order in logs

$$
\log W_{j c t}=\log \alpha_{c}+\sum_{k} \gamma_{j k} \log L_{k c t}, j=s, u \text { and } k=s, u
$$

\footnotetext{
${ }^{17}$ At this point, I am not specifying a functional form for the production function. It might be useful later on to do so, as this will help in calculating the different elasticities of interest. For example, Acemoglu, Autor, and Lyle (2004) use CES production function in their analysis of the effects of the increase of women's labor supply on wages.
} 
where $\gamma_{j k}=d \log W_{j c t} / d \log L_{k c t}$ for $j=s, u$ and $k=s, u$. The parameter $\gamma_{j k}$ for $j=k$ represents the response of the wages of group $j$ to an increase in their own labor supply, and $\gamma_{j k}$ for $j \neq k$ represents the response of the wages of group $j$ to an increase in the labor supply of group $k$.

In a competitive labor market, with one factor of production, an increase in the supply of labor is expected to decrease real wages and increase employment. However, at least in the short run, because of labor market frictions the adjustment to the new equilibrium might not be instantaneous. Figure 2 illustrates such a scenario. Imagine an economy in equilibrium with labor supply $L_{o}$ and $W_{0}$. An exogenous influx of workers increases the supply to $L_{1}^{*}$. If the market clears, wages will fall to $W_{1}^{*}$ and the new employment level will be at $L_{1}^{*}$. However, because new jobs are not available in the short run the market does not clear and actual employment rises only to $L_{1}$. Alternatively, we could assume that wages, rather than employment, are rigid and adjust slowly. However, in the case of the Palestinian market the adjustment through employment seems more reasonable especially because of the high number of unemployed men observed in the data (Table 1,3) after the supply shock. ${ }^{18}$

Formally, assume that current employment adjusts according to the following mechanism

$$
\log L_{j c t}=\sigma_{j} \log L_{j c t-1}+\left(1-\sigma_{j}\right) \log L_{j c t}^{*}, j=s, u
$$

\footnotetext{
${ }^{18}$ The Palestinian market is not unionized, so assuming that wages are rigid for the unskilled workers is hard to justify. However, the wages of skilled workers may be rigid because of contracting.
} 
where $\sigma_{j}$ measures the adjustment of employment of skill group $j$. For example, if $\sigma_{j}=0$ the labor market clears and their is no increase in the number of unemployed men. If on the other hand, $\sigma_{j}=1$, then wages do not change and the amount of unemployed men will equal the supply shock.

Substituting (9) in (8) yields

$\log W_{j c t}=\log \alpha_{c}+\sum_{k} \gamma_{j k}\left[\sigma_{k} \log L_{k c t-1}+\left(1-\sigma_{k}\right) \log L_{k c t}^{*}\right], j=s, u$ and $k=s, u$

where $L^{*}$ measures the new supply of labor that corresponds to the desired wage $W^{*}$. Notice that all terms on the right-hand-side of equation (10) are predetermined or exogenous and hence it is the basis for our empirical specifications.

To complete the empirical specification, the term $\log \alpha_{c}$ is replaced with city fixed effects, time fixed effects are added to control for the time trend, and a vector of personal characteristics is included. Specifically, let $\log W_{i j c t}$ be the natural logarithm of the real daily wage for an individual $i$ of skill $j(j=s, u)$ who lives in city $c(c=1, \ldots, 11)$, is observed in quarter $q(q=1, \ldots 4)$ in year $t$ $(t=2000, \ldots, 2004) .{ }^{19}$ Wages earned in Israel are excluded from the sample. I estimate jointly the following system of equations

\footnotetext{
${ }^{19}$ The subscript $q$ is suppressed for convenience.
} 


$$
\begin{aligned}
\log L_{\text {iuct }}= & \tau_{u} \log L_{\text {iuct-1 }}+\phi_{u} \log L_{i u c t}^{*}+q \delta_{u}+C_{i} \eta_{u}+X_{c t} \omega_{u} \\
& +Z_{\text {iuct }} \nu_{u}+\vartheta_{\text {iuct }} \\
\log W_{\text {iuct }}= & \pi_{1} \log L_{i u c t-1}+\pi_{2} \log L_{i u c t}^{*}+\pi_{3} \log L_{i s c t-1}+\pi_{4} \log L_{i s c t}^{*} \\
& +q \beta_{u}+C_{i} \mu_{u}+X_{c t} \xi_{u}+Z_{\text {iuct }} \theta+v_{\text {iuct }}
\end{aligned}
$$

$$
\begin{aligned}
\log L_{i s c t}= & \tau_{s} \log L_{i s c t-1}+\phi_{s} \log L_{i s c t}^{*}+q \delta_{s}+C_{i} \eta_{s}+X_{c t} \omega_{s} \\
& +Z_{i s c t} \nu_{s}+\vartheta_{i s c t} \\
\log W_{i s c t}= & \rho_{1} \log L_{i s c t-1}+\rho_{2} \log L_{i s c t}^{*}+\rho_{3} \log L_{i u c t-1}+\rho_{4} \log L_{i u c t}^{*} \\
& +q \beta_{s}+C_{i} \mu_{s}+X_{c t} \xi_{s}+Z_{\text {isct }} \theta+v_{\text {iuct }}
\end{aligned}
$$

In equations (11)-(14) an unskilled individual has 12 years of education or less. $q$ is a vector of quarter fixed effects interacted with year fixed effects. This vector controls for events that affected the entire West Bank but did not vary across cities. Such events include closures of the borders, and terror attacks in Israel. $C_{i}$ is a vector of city fixed effects, and $X_{c t}$ is a vector of instability measures that vary across cities and over time. The vector $Z_{i j c t}$ includes age group fixed effects, a marital status dummy, and might include other controls such as industry dummies.

The measure of labor supply $L^{*}$, and actual employment $L_{t}$ are described in equations (15) and (16). In what follows, $D_{j c t}$ is the number of workers employed 
locally (of skill $j$ at time $t$ ), $U_{j c t}$ is the number of unemployed men, and $I_{j c t}$ is the number of workers employed in Israel.

$$
\begin{gathered}
L_{j c t}^{*}=D_{j c t}+U_{j c t} /\left(D_{j c t}+U_{j c t}+I_{j c t}\right) \\
L_{j c t}=D_{j c t} /\left(D_{j c t}+U_{j c t}+I_{i j c t}\right)
\end{gathered}
$$

Is it plausible to assume that $L^{*}$ is exogenous? The main concern is that even after controlling for some instability measures in the vector $X_{c t}$, the error term will still include unobserved components that are correlated with $L^{*}$ and that affect the dependent variable directly. Two examples of such omitted variables are the number of internal checkpoints and the construction of the separation wall around some of the cities in the sample period (I am still trying to collect the data). Since the expected sign of $\pi_{2}$ and $\rho_{2}$ is negative and both variables are positively correlated with $L^{*}$, we would expect the bias to go downward. This implies that the estimates of the own labor demand elasticities that I report are a lower bound.

The structural parameters, that the model implies in equations (9) and (10), are estimated using optimal minimum-distance (OMD) estimation (Chamberlain (1984)). Let $\Gamma$ denote the vector of relevant regression coefficients from equations (11)-(14)

$$
\Gamma=\left[\tau_{u}, \phi_{u}, \pi_{1}, \pi_{2}, \pi_{3}, \pi_{4}, \tau_{s}, \phi_{s}, \rho_{1}, \rho_{2}, \rho_{3}, \rho_{4}\right]^{\prime}
$$


The model implies the following restrictions on the regression coefficients across the different equations

$$
\begin{aligned}
& \tau_{u}=\sigma_{u} ; \phi_{u}=1-\sigma_{u} ; \pi_{1}=\gamma_{u u} \sigma_{u} ; \pi_{2}=\gamma_{u u}\left(1-\sigma_{u}\right) ; \pi_{3}=\gamma_{u s} \sigma_{s} \\
& \pi_{4}=\gamma_{u s}\left(1-\sigma_{s}\right) ; \tau_{s}=\sigma_{s} ; \phi_{s}=1-\sigma_{s} ; \rho_{1}=\gamma_{s s} \sigma_{s} ; \rho_{2}=\gamma_{s s}\left(1-\sigma_{s}\right) \\
& \rho_{3}=\gamma_{s u} \sigma_{u} ; \rho_{4}=\gamma_{s u}\left(1-\sigma_{u}\right)
\end{aligned}
$$

Optimal minimum-distance estimates are obtained by minimizing the following quadratic form (Deschenes, 2006)

$$
\widehat{\Omega}=\min _{\Omega}[\widehat{\Gamma}-f(\Omega)] \widehat{W}[\widehat{\Gamma}-f(\Omega)]
$$

where $\widehat{\Omega}$ is the vector of estimated regression coefficients, $f(\Omega)$ is the vector of restrictions imposed by the model, and $\widehat{W}$ is the inverse of the estimated covariance matrix of $\widehat{\Gamma}$, and $\Omega$ is the vector of the model parameters

$$
\Omega=\left[\sigma_{u}, \sigma_{s}, \gamma_{u u}, \gamma_{s s}, \gamma_{u s,}, \gamma_{s u}\right]^{\prime}
$$

Chamberlain (1984) showed that under mild regularity conditions, the OMD estimator is asymptotically efficient.

Table 7 report the estimates of the parameters $\sigma_{u}$ and $\sigma_{s}$. In column 1 and 2 the potential cross effects between unskilled and skilled workers in the wage equa- 
tions are constrained to zero, and in column 3 and 4 they are not constrained. The estimates reveal that the employment adjustment is different between both skill groups. Past levels of employment for unskilled men are highly correlated with current employment which implies that the creation of new employment opportunities for this group is slow and the level of unemployment due to the supply shock is high. The implications are different for skilled men. The correlation of the supply measure with current employment is higher, implying that the level of unemployment due to the supply shock among this group is lower and that the market is clearing relatively faster.

Table 8 reports the effects of the supply shock on the wages. $\gamma_{u u}$, the response of unskilled wages to an increase in unskilled labor, is the only parameter that is statistically significant. Column 1 and 2 restrict the cross effects between skill groups to zero and column 3 and 4 allow them to be free. The estimates when instability measures and industry dummies are included (column 1, row 3) imply that a 10 percent increase in the supply of unskilled labor reduces their wages by about 2 percent. The point estimate, when the restriction on the cross effects is removed, is slightly smaller in magnitude and remains statistically significant (when all controls are added). It is interesting to notice that adding industry dummies increases the point estimates (in absolute value) and reduces the standard errors indicating that the changes in wages are occurring within industries.

\section{Conclusions and Further Work}

The main objective of this study is to identify the effects of supply shocks on 
wages and employment patterns in the West Bank, and to use these estimates to analyze counterfactual border policies that are at the center of any future agreement between Israel and the Palestinians. The preliminary analysis uses East Jerusalem as a control group and the rest of the cities in the West Bank as the treated group. Assuming that political instability affects East Jerusalem and the rest of the West Bank similarly, the overall effect of the demand shock on wages can be differenced out. The fact that East Jerusalem experience a much lower supply shock compared to other cities in the West Bank identifies a lower bound of the true parameter.

The second approach substitutes the assumption that the demand shocks are similar across West Bank cities in an assumption that observable indicators adequately capture any demand shock differences between West Bank cities. Moreover, it uses variations in the labor supply in each city over time to estimate the wage elasticities, with respect to an increase in the labor supply. Since we can distinguish workers by skill groups, this approach allows us to investigate the potential effects among the different skill groups.

There are important differences between the two approaches related to the source of variation that is used for identification. The first strategy views the supply shock as a one time policy change and uses cross-city differences in wages and employment to identify the effects on labor market outcomes. The second strategy uses variations in the local supply of labor within a city and over time. It takes advantage of the off-trend variations that a city experience to identify the effects of an increase in the local labor supply.

The results of both approaches suggest that a 10 percent increase in the do- 
mestic labor supply of unskilled workers reduces their wages by about 2-5 percent. The wages of skilled workers do not seem to be negatively affected. In terms of employment, the two skill groups reveal different patterns. While the adjustment of skilled workers happens relatively fast, the unemployment rates among unskilled workers are high and persistent. This suggests that the process of creating new employment opportunities in the West Bank for unskilled workers is very slow and should be taken into account for future policy considerations.

As for future work the parameters estimated will be used to analyze counterfactual policies regarding border controls between Israel and the Palestinians. For example, the economic implications of a complete closure of the borders between the parties, and the expected consequences of the return of Palestinian refugees to the West Bank. 


\section{References}

[1] Acemoglu, D., Autor, D. and D. Lyle, "Women, War, and Wages: The Effects of Female Labor Supply on the Wage Structure at Midcentury," Journal of Political Economy, 112(3), June 2004: 497-551.

[2] Angrist, J. D. "Short-Run Demand for Palestinian Labor," Journal of Labor Economics, 14(3), July 1996: 425-453.

[3] Angrist, J. D. "Empirical Strategies in Labor Economics," In Orley Ashenfelter and David Card, editors, Handbook of Labor Economics, vol. 3A, 1999: 1278-1284.

[4] Aranki, T. N. "The Effect of Israeli Closure Policy on Wage Earnings in the West Bank and Gaza Strip," Örebro University, Department of Economics, Working Paper no.4, 2004.

[5] Aranki, T. N. "The Impact of Foreign Workers in Israel on the Palestinian Labor Market," Örebro University, Department of Economics, Working Paper, 2004 .

[6] Borjas, G. J. "The Labor Demand Curve is Downward Sloping: Reexamining the Impact of Immigration on the Labor Market," Quarterly Journal of Economics, 118(4), November 2003: 1335-1374.

[7] Borjas, G. J. "The Economics of Immigration," Journal of Economic Literature, 32(4), December 2004: 1667-1717. 
[8] Borjas G. J. and Freeman, R. and K. Lawrence, F. "Searching for the Effect of Immigration on the Labor Market," American Economic Review, 86(2), May 1996: 246-251

[9] Card, D. " The Impact of the Mariel Boatlift on the Miami Labor Market," Industrial and Labor Relations Review, 43(2), January 1990: 245-257.

[10] Card, D. and A. Kruger, "Minimum Wages and Employment: A Case Study of the Fast-Food Industry in New Jersey and Pennsylvania," American Economic Review, 84(4), September 1994: 772-793.

[11] Chamberlain, G. "Panel Data," In Zvi Griliches and Michael Intrilligator, editors, The Handbook of Econometrics, vol. 2, North-Holland, Amsterdam and New York, 1984.

[12] Deschenes, O. "Estimating the Effect of Family Background on the Return to Schooling," Forthcoming in the Journal of Business and Economic Statistics.

[13] Friedberg, R. and J. Hunt, "The Impact of Immigrants on Host Country Wages, Employment and Growth," Journal of Economic Perspectives, 9(2), Spring 1995: 23-44.

[14] Friedberg, R. and R. Sauer, "Does the Presence of Foreign Guest Workers in Israel Harm Palestinians from the West Bank and Gaza Strip?," Working Paper, June 2004.

[15] Jaeger D. and D. Paserman, "The Cycle of Violence? An Empirical Analysis of Fatalities in the Palestinian-Israeli Conflict," Working Paper, October 2005. 
[16] Kleiman, E. "The Flow of Labor Services from the West Bank and Gaza to Israel," The Hebrew University of Jerusalem, Department of Economics Working Paper, no. 260, 1992.

[17] Lalonde, R. J., and R. Topel, "Labor Market Adjustments to Increased Immigration," in J. Abowd and R. Freeman, eds., Immigration, Trade, and the Labor Market, Chicago, University of Chicago Press, 1991.

[18] Ottaviano, G. and G. Peri, "Rethinking the Gains from Immigration: Theory and Evidence from the U.S.," NBER Working Paper no. 11672, September 2005 .

[19] Oaxaca, R. L. "Male-Female Wage Differentials in Urban Labor Markets," International Economic Review, 14, October 1973: 693-709.

[20] Ruppert B. E. "The Impact of Israeli Border Policy on the Palestinian Labor Market," Economic Development and Cultural Change, 51(3): April 2003: 657-676.

[21] Sayre, E. "The Labor-Market Effects of Palestinian Return Migration," Working Paper, May 2003. 
Figure 1: Number of Palestinians employed in Israel.

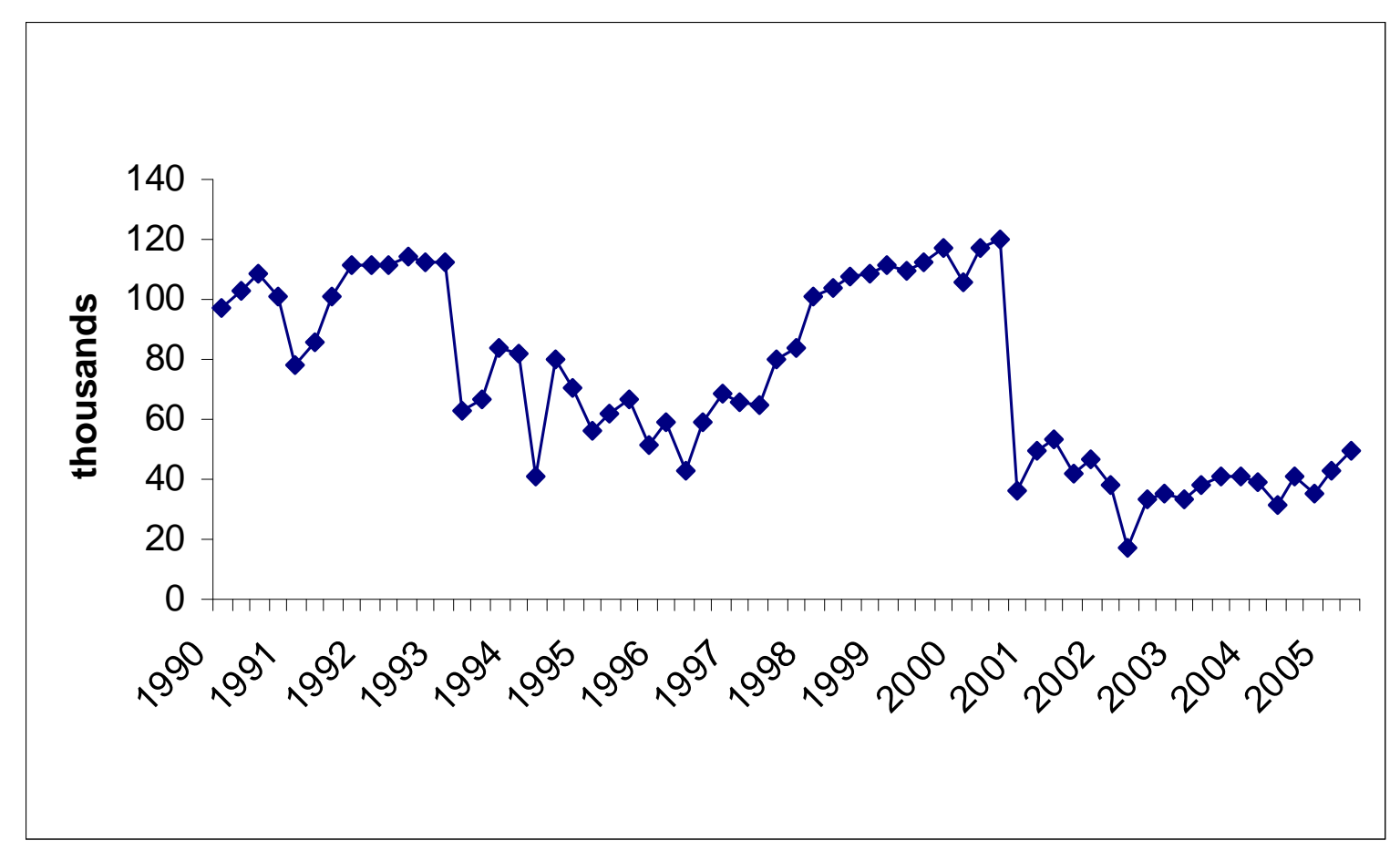

Source: Bank of Israek, Data Series Database, Labor Force, Employment and Wages, 1990-2005. 


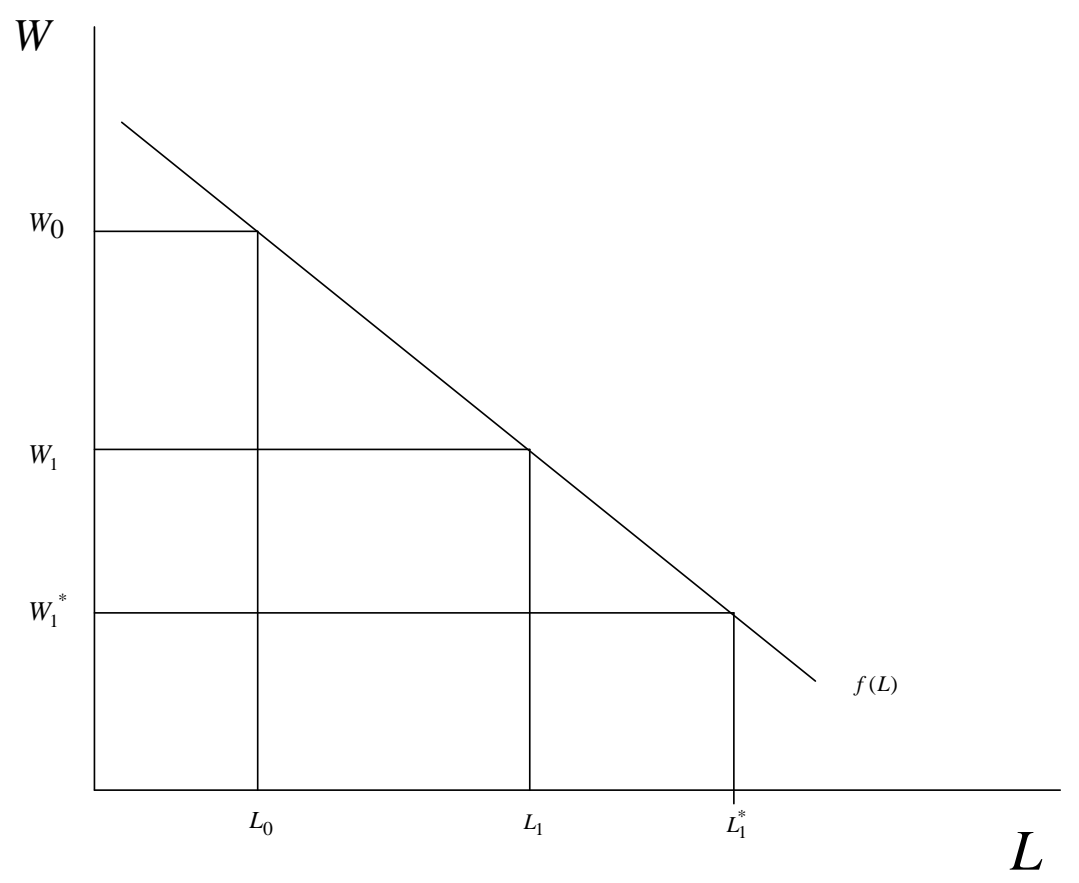

Figure 2: The adjustment of the labor market to an increase in the supply of labor. 
Table 1: Descriptive Statistics

Sample of men, aged 18-65, residents of the West Bank, 1997-2004.

\begin{tabular}{cccccc}
\hline & $\begin{array}{c}\text { Sample } \\
\text { size }\end{array}$ & $\begin{array}{c}\text { Years of } \\
\text { schooling }\end{array}$ & $\begin{array}{c}\text { Labor force } \\
\text { participation }\end{array}$ & $\begin{array}{c}\text { Employment } \\
\text { rate }\end{array}$ & Work in \\
\hline 1997 & 14,537 & 9.75 & $76 \%$ & $59 \%$ & $31 \%$ \\
1998 & 19,026 & 9.87 & $77 \%$ & $66 \%$ & $33 \%$ \\
1999 & 18,746 & 9.87 & $78 \%$ & $69 \%$ & $34 \%$ \\
2000 & 18,655 & 9.97 & $79 \%$ & $66 \%$ & $33 \%$ \\
2001 & 16,879 & 10.01 & $75 \%$ & $49 \%$ & $23 \%$ \\
2002 & 13,980 & 10.12 & $70 \%$ & $40 \%$ & $11 \%$ \\
2003 & 16,219 & 10.27 & $70 \%$ & $46 \%$ & $14 \%$ \\
2004 & 15,731 & 10.34 & $70 \%$ & $46 \%$ & $15 \%$ \\
\hline
\end{tabular}

Note: Self employed and unpaid home workers are excluded from the sample.

The employment rate and the share of workers who commute to Israel are calculated as the share from the whole population of men, aged 18-65. 


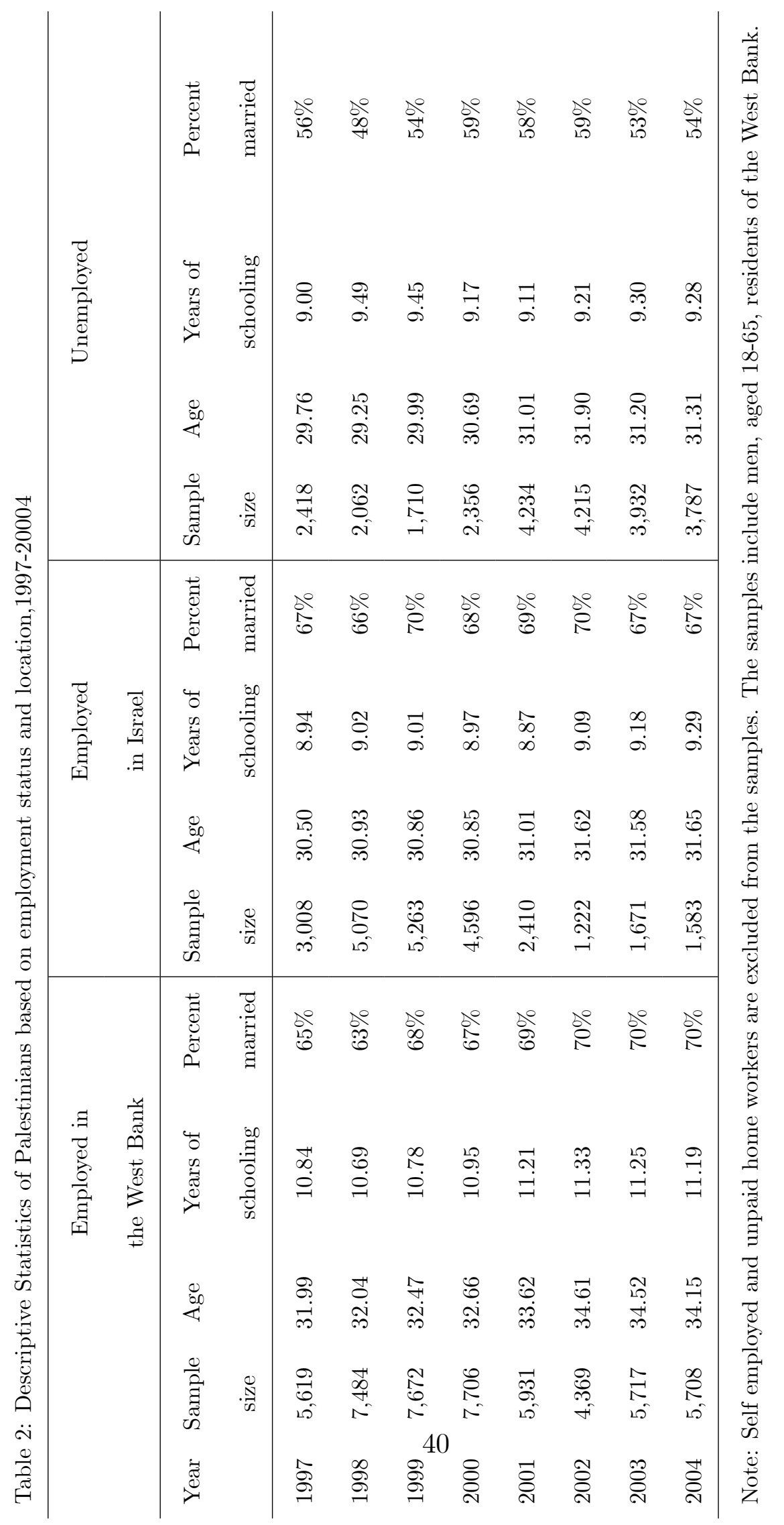




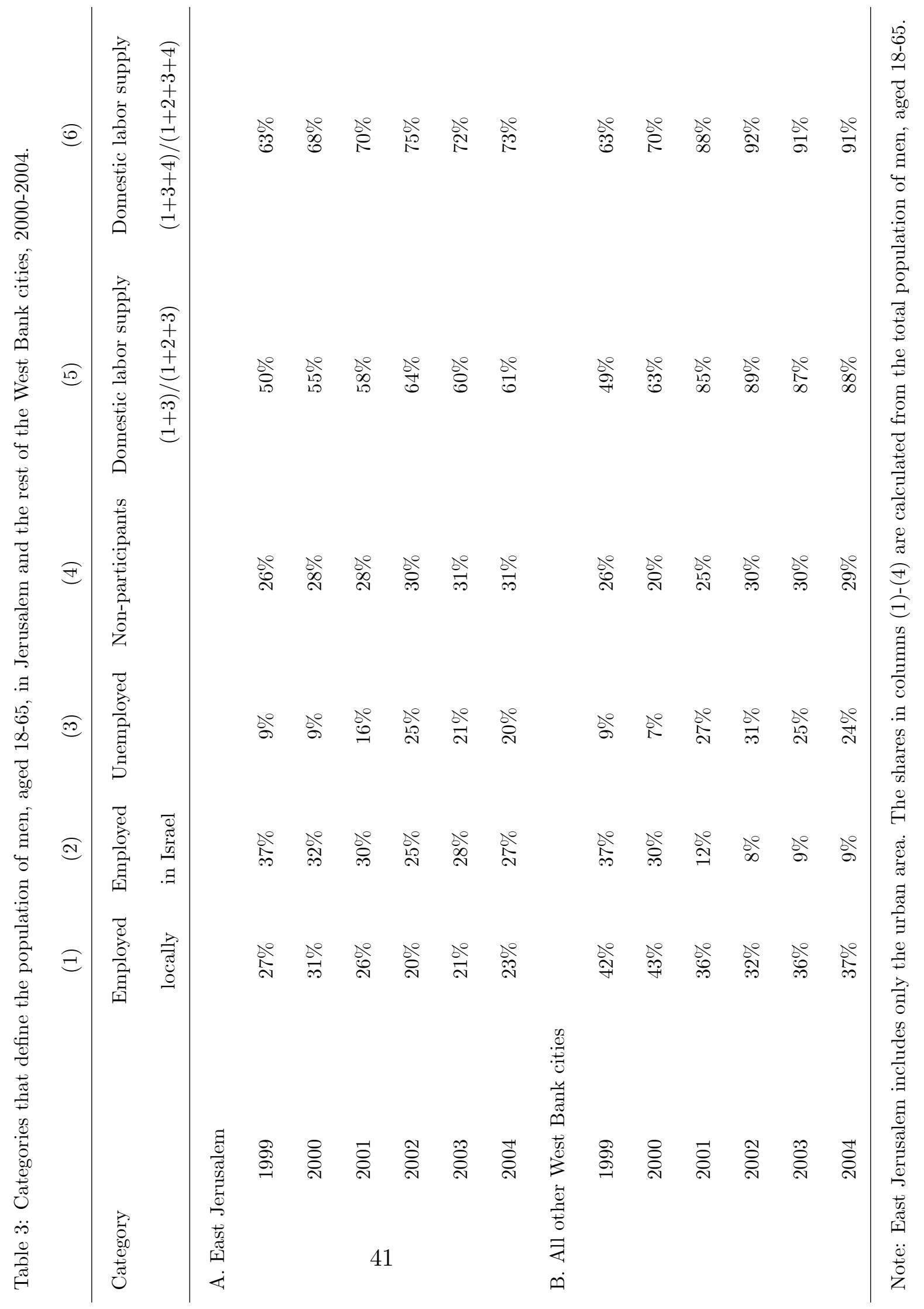


Table 4: Workplace location of workers in the West Bank, 2000-2004

\begin{tabular}{cccc}
\hline & $(1)$ & $(2)$ & $(3)$ \\
\hline Workplace location & Same city of residence & In a different city & Israel \\
& & in the West Bank & \\
\hline 2000 & $54 \%$ & $9 \%$ & $37 \%$ \\
2001 & $54 \%$ & $8 \%$ & $38 \%$ \\
2002 & $66 \%$ & $12 \%$ & $22 \%$ \\
2003 & $66 \%$ & $11 \%$ & $23 \%$ \\
2004 & $68 \%$ & $10 \%$ & $22 \%$ \\
\hline
\end{tabular}

Note: The share of workers in each location is calculated from the population of employed Palestinians. Unemployed workers are excluded because they report no workplace location. 
Table 5: The impact of changes in the local supply of labor on wages using a difference-in-difference approach. Dependent variable is the log real daily wage in the West Bank (excluding wages in Israel).
(1)
(2)

(3)

(4)

(5)

(6)

Full sample Full sample Full sample Unskilled Unskilled Unskilled

\begin{tabular}{ccccccc}
\hline 2001 & -0.047 & -0.059 & -0.038 & -0.032 & -0.030 & 0.006 \\
& $(0.072)$ & $(0.071)$ & $(0.071)$ & $(0.083)$ & $(0.083)$ & $(0.082)$ \\
2002 & -0.214 & -0.162 & -0.136 & -0.259 & -0.238 & -0.187 \\
& $(0.036)$ & $(0.034)$ & $(0.034)$ & $(0.044)$ & $(0.042)$ & $(0.043)$ \\
2003 & -0.221 & -0.220 & -0.207 & -0.263 & -0.267 & -0.224 \\
& $(0.035)$ & $(0.033)$ & $(0.033)$ & $(0.041)$ & $(0.040)$ & $(0.040)$ \\
2004 & -0.210 & -0.185 & -0.215 & -0.217 & -0.226 & -0.255 \\
& $(0.037)$ & $(0.033)$ & $(0.033)$ & $(0.043)$ & $(0.041)$ & $(0.041)$ \\
controls & No & Yes & Yes & No & Yes & Yes \\
Industry & No & No & Yes & No & No & Yes \\
N & 27,062 & 27,058 & 27,058 & 17,655 & 17,654 & 17,654 \\
\hline
\end{tabular}

Note: Huber-White standard errors at the five percent significance level are reported in parentheses.

The second column includes age, education, marital status, and quarter controls. The third column adds industry dummies. The fifth column includes age, marital status, and quarter controls, and the sixth column adds industry dummies. The industries are: 1. agriculture, 2. manufacturing,

3. construction, 4. commerce, hotels and restaurants, 5. transport, storage and communication, and 6. services. 
Table 6: The impact of changes in the local supply of labor on employment using a difference-in-difference approach.

Dependent variable is a non-employment dummy.
(1)
(2)
(3)
(4)

Full sample Full sample Unskilled Unskilled

\begin{tabular}{ccccc}
\hline 2001 & 0.178 & 0.172 & 0.225 & 0.218 \\
& $(0.020)$ & $(0.019)$ & $(0.023)$ & $(0.021)$ \\
2002 & 0.155 & 0.143 & 0.182 & 0.182 \\
& $(0.023)$ & $(0.021)$ & $(0.025)$ & $(0.024)$ \\
2003 & 0.134 & 0.122 & 0.151 & 0.148 \\
& $(0.022)$ & $(0.020)$ & $(0.024)$ & $(0.023)$ \\
2004 & 0.135 & 0.121 & 0.144 & 0.141 \\
& $(0.022)$ & $(0.020)$ & $(0.025)$ & $(0.023)$ \\
controls & No & Yes & No & Yes \\
N & 81,465 & 81,453 & 61,541 & 61,535 \\
\hline
\end{tabular}

Note: Huber-White standard errors at the five percent significance level are reported in parentheses. The second column includes age, education, marital status, and quarter controls. The fourth column includes age, marital status, and quarter controls. 
Table 7: The effects of an increase in the labor supply on employment.

Dependent variable is the employment rate in a locality. The supply is calculated as the share of local labor force participants from total labor force participants.

\begin{tabular}{lcccc}
\hline & \multicolumn{2}{c}{ Cross effects } & \multicolumn{2}{c}{$\begin{array}{c}\text { Cross effects } \\
\text { not constrained }\end{array}$} \\
\hline & $(1)$ & $(2)$ & $(3)$ & $(4)$ \\
\hline constrained to zero & $\sigma_{u}$ & $\sigma_{u}$ & $\sigma_{s}$ \\
\hline 1. Basic specification & 0.658 & 0.215 & 0.652 & 0.267 \\
& $(0.063)$ & $(0.066)$ & $(0.064)$ & $(0.061)$ \\
& & & & 0.216 \\
& 0.659 & 0.203 & 0.651 & $(0.072)$ \\
& $(0.063)$ & $(0.074)$ & $(0.063)$ & \\
& & & & 0.258 \\
& & & 0.634 & $(0.064)$ \\
\hline
\end{tabular}

Note: Standard errors at the five percent significance level are reported in parentheses.

Unskilled workers are those with 12 years of education or less. The specification in row 1 includes time and city fixed effects, and skill, age, and marital status dummies. Row 2 augments this specification by adding information on fatalities, and number of days under curfew per quarter in each city. The third specification adds industry dummies. The industries are: 1. agriculture, 2. manufacturing, 3. construction, 4. commerce hotels and restaurants, 5. transport, storage and communication, and 6. services. All regressions are weighted using the sample weights. 
Table 8: The effects of an increase in the labor supply on wages. Dependent variable is the log real daily wage in the West Bank. The supply is calculated as the share of local labor force participants from total labor force participants.

\begin{tabular}{lcccc}
\hline & \multicolumn{2}{c}{ Cross effects } & \multicolumn{2}{c}{$\begin{array}{c}\text { Cross effects } \\
\text { not constrained }\end{array}$} \\
\hline & $(1)$ & $(2)$ & $(3)$ & $(4)$ \\
& $\gamma_{u u}$ & $\gamma_{s s}$ & $\gamma_{u u}$ & $\gamma_{s s}$ \\
\hline 1. Basic specification & $-0.196^{*}$ & 0.285 & -0.112 & 0.347 \\
& $(0.087)$ & $(0.176)$ & $(0.076)$ & $(0.173)$ \\
& & & & 0.325 \\
2. Adding instability measures & $-0.186^{*}$ & 0.267 & -0.120 & $(0.180)$ \\
& $(0.080)$ & $(0.176)$ & $(0.070)$ & \\
3. Adding industry dummies & $-0.205^{*}$ & 0.268 & $-0.169^{*}$ & 0.340 \\
& $(0.078)$ & $(0.176)$ & $(0.069)$ & $(0.177)$ \\
\hline
\end{tabular}

Note: Standard errors at the five percent significance level are reported in parentheses.

Unskilled workers are those with 12 years of education or less. The specification in row 1 includes time and city fixed effects, and skill, age, and marital status dummies. Row 2 augments this specification by adding information on fatalities, and number of days under curfew per quarter in each city. The third specification adds industry dummies. The industries are: 1. agriculture, 2. manufacturing, 3. construction, 4. commerce hotels and restaurants, 5 . transport, storage and communication, and 6. services. All regressions are weighted using the sample weights. 